\title{
Sustainable Urban Solid Waste Management in an Integrated Value Chain Perspective: Closing the Cycle \& Remanufacturing Modular Designed Goods
}

\section{Meine Pieter van Dijk}

Professor of urban management at ISS of Erasmus University in Rotterdam, Netherlands

${ }^{*}$ Corresponding author: Meine Pieter van Dijk, professor of urban management at ISS of Erasmus University in Rotterdam, Netherlands, Tel: 0031610896982; E-mail: m.vandijk@unesco-ihe.org

Received date: June 23, 2014; Accepted date: June 25, 2014; Published date: June 30, 2014

Copyright: (c) 2014 Dijk MP. This is an open-access article distributed under the terms of the Creative Commons Attribution License, which permits unrestricted use, distribution, and reproduction in any medium, provided the original author and source are credited.

\section{Editorial}

Sustainability of urban Solid Waste Management (SWM) is high on the agenda of city managers. Municipalities in particular in developing countries are often not capable of meeting the demand for urban services, let alone achieve sustainable solid waste cycle management. Private Public Partnerships (PPP) and community-based initiatives are becoming increasingly important as a means of addressing the deficiencies of the formal system. However, what strikes when looking at recent papers on aspects of solid waste collection is that very few look at is as an integrated issue, concerning a value chain, from the creation of products, their use and waste, until the possible reuse and recycling. This is in particular necessary if we want to make SWM more sustainable. Taking sustainability to mean: thinking about the people, the planet and the profit sector (ppp) in an integrated way.

The challenge is to educate the people, government officials and private waste companies involved that there is another way of looking at solid waste management. In terms of behavioural economics we need to find the incentives that nudge them in the desired direction. The consumers should minimize and separate, the collectors should get everything and bring it to the right place to be decomposed and the government should facilitate the process and provide the incentives, rather than introducing more regulation.
And we should all learn the jargon: we need green design, promote remanufacturing and curb inefficient flows of single-use goods. The slogan is recovering the value from end-of-life products and manufacture like Xerox company new products containing reused components. In the circular economy we increase the use cycles, whether in the smart city of the future, the re-factory of multi-cycle products or the closed loop utility of water and sanitation. Increased recyclability makes solid waste a resource, which not only generates energy, regenerates raw materials, but also co-generates recyclable parts for our cars and computers. The challenge is remanufacturing multiple cycle products using the energy generated in the decomposition process. This requires not only incentives for the consumers, the government officials and private waste companies concerned, but also for the designers, the manufacturers and the companies disaggregating the waste. In an integrated approach this would be taken into account and that is the research angle we have chosen: study the efforts to achieve a closed cycle for water and sanitation, for energy and other goods in the smart city of the future, which is not only facing the challenges of improved service delivery, of collecting more financial resources and dealing with increased pollution, but also of increased global competition, climate change and a dynamic global environment, where new ideas pop up every day, somewhere! 